\title{
EQUIVALENT STATEMENTS OF A HILBERT-TYPE INTEGRAL INEQUALITY WITH THE EXTENDED HURWITZ ZETA FUNCTION IN THE WHOLE PLANE
}

\author{
AIZHEN WANG AND BICHENG YANG*
}

\begin{abstract}
By using the way of real analysis and the weight functions, a few equivalent statements of a Hilbert-type integral inequality with the nonhomogeneous kernel in the whole plane are obtained. The constant factor related the extended Hurwitz zeta function is proved to be the best possible. As applications, a few equivalent statements of a Hilbert-type integral inequality with the homogeneous kernel in the whole plane are deduced. We also consider the operator expressions and some corollaries.
\end{abstract}

Mathematics subject classification (2010): 26D15, 65B10.

Keywords and phrases: Hilbert-type integral inequality, weight function, equivalent statement, operator, Hurwitz zeta function.

\section{REFERENCES}

[1] G. H. Hardy, J. E. Littlewood, G. Pòlya, Inequalities, Cambridge University Press, Cambridge, USA, 1934.

[2] B. C. YANG, The norm of operator and Hilbert-type inequalities, Science Press, Beijing, China, 2009.

[3] B. C. YANG, Hilbert-Type Integral Inequalities, Bentham Science Publishers Ltd., The United Arab Emirates, 2009.

[4] B. C. YANG, On the norm of an integral operator and applications, J. Math. Anal. Appl., 321 (2006), $182-192$.

[5] J. S. XU, Hardy-Hilbert's inequalities with two parameters, Advances in Mathematics, 36 (2), 63-76.

[6] B. C. YANG, On the norm of a Hilbert's type linear operator and applications, J. Math. Anal. Appl., 325 (2007), 529-541.

[7] D. M. XIN, A Hilbert-type integral inequality with the homogeneous kernel of zero degree, Mathematical Theory and Applications, 30 (2) (2010), 70-74.

[8] B. C. YANG, A Hilbert-type integral inequality with the homogenous kernel of degree 0, Journal of Shandong University (Natural Science), 45 (2) (2010), 103-106.

[9] L. DeBnAth, B. C. YANG, Recent developments of Hilbert-type discrete and integral inequalities with applications, International Journal of Mathematics and Mathematical Sciences, Volume 2012, Article ID 871845, 29 pages.

[10] Y. Hong, On the structure character of Hilbert's type integral inequality with homogeneous kernal and applications, Journal of Jilin University (Science Edition), 2017, 55 (2), 189-194.

[11] M. TH. RASSiAS, B. C. YANG, On half-discrete Hilbert's inequality, Applied Mathematics and Computation, 220 (2013), 75-93.

[12] B. C. YANG, M. KRNIC, A half-discrete Hilbert-type inequality with a general homogeneous kernel of degree 0, Journal of Methematical Inequalities, 6 (3) (2012), 401-417.

[13] TH. M. Rassias, B. C. YAnG, A multidimensional half-discrete Hilbert-type inequality and the Riemann zeta function, Applied Mathematics and Computation, 225 (2013), 263-277.

[14] M. TH. Rassias, B. C. YANG, On a multidimensional half-discrete Hilbert-type inequality related to the hyperbolic cotangent function, Applied Mathematics and Computation, 242 (2013), 800-813. 
[15] M. TH. Rassias, B. C. YANG, A multidimensional Hilbert-type integral inequality related to the Riemann zeta function, Applications of Mathematics and Informatics in Science and Engineering (N. J. Daras, ed.), Springer, New York, 417-433, 2014.

[16] B. C. YANG, A new Hilbert-type integral inequality, Soochow Journal of Mathematics, 33 (4) (2007), 849-859.

[17] Z. Q. WANG, D. R. Guo, Introduction to special functions, Science Press, Beijing, China, 1979.

[18] B. HE, B. C. YANG, On a Hilbert-type integral inequality with the homogeneous kernel of 0-degree and the hypergeometrc function, Mathematics in Practice and Theory, 40 (18) (2010), 105-211.

[19] B. C. YANG, A new Hilbert-type integral inequality with some parameters, Journal of Jilin University (Science Edition), 46 (6) (2008), 1085-1090.

[20] B. C. YANG, A Hilbert-type integral inequality with a non-homogeneous kernel, Journal of Xiamen University (Natural Science), 48 (2) (2008), 165-169.

[21] B. HE, B. C. YANG, On an inequality concerning a non-homogeneous kernel and the hypergeometric function, Tamsul Oxford Journal of Information and Mathematical Sciences, 27 (1) (2011), 75-88.

[22] B. YANG, A reverse Hilbert-type integral inequality with a non-homogeneous kernel, Journal of Jilin University (Science Edition), 49 (3) (2011), 437-441.

[23] Z. T. XIE, Z. ZENG, Y. F. SUn, A new Hilbert-type inequality with the homogeneous kernel of degree -2, Advances and Applications in Mathematical Sciences, 12 (7) (2013), 391-401.

[24] Q. L. HuAng, S. H. Wu, B. C. YAng, Parameterized Hilbert-type integral inequalities in the whole plane, The Scientific World Journal, Volume 2014, Article ID 169061, 8 pages.

[25] Z. Zhen, K. Raja RAma GANDhI, Z. T. XIE, A new Hilbert-type inequality with the homogeneous kernel of degree -2 and with the integral, Bulletin of Mathematical Sciences \& Applications, 3 (1) (2014), 11-20.

[26] M. TH. RAssias, B. C. YANG, A Hilbert-type integral inequality in the whole plane related to the hyper geometric function and the beta function, Journal of Mathematical Analysis and Applications, 428 (2): 1286-1308 (2015).

[27] X. Y. HuAnG, J. F. CAO, B. HE, B. C. YANG, Hilbert-type and Hardy-type integral inequalities with operator expressions and the best constants in the whole plane, Journal of Inequalities and Applications (2015), 2015:129.

[28] Z. H. GuL, B. C. YANG, A Hilbert-type integral inequality in the whole plane with a nonhomogeneous kernel and a few parameters, Journal of Inequalities and Applications (2015), 2015:314.

[29] J. C. KuAng, Real and functional analysis (Continuation), (second volume), Higher Education Press, Beijing, China, 2015.

[30] J. C. KuAng, Applied inequalities, Shangdong Science and Technology Press, Jinan, China, 2004. 